\title{
The Conversion from Continuous Sufentanil Infusion to Oral Retarded Opioid Medication: Beware of the Equi-Analgesic Opioid Ratios - A Case Series
}

\author{
Jauch J, Pfau G, Kretzschmar M, Bergmann A, Schilling T* and Brinkers M \\ Department of Anesthesiology and Intensive Care Medicine, Otto-von-Guericke-University Magdeburg, Germany
}

Submission: February 15, 2017; Published: March 30, 2017

*Corresponding author: Thomas Schilling, Department of Anesthesiology and Intensive Care Medicine, Otto-von-Guericke-University Magdeburg, Germany, Email: Thomas.Schilling@med.ovgu.de

\begin{abstract}
Background: Sufentanil has an outstanding place in clinical practice and one cannot think of surgery or intensive care therapy without it. However, the routine use of continuous sufentanil infusion may cause severe problems if stabilized patients are discharged from the ICU after surgical treatment and need to be converted to oral opioids.

Aim \& method: Here we report our experiences with a series of six patients that we have converted from intravenous sufentanil to oral morphine.

Cases: In 6 cases, we report intensive care (ICU) patients after surgical or medical therapy, who received sufentanil infusion for analgosedation. The patients were between 45 and 68 years old. It can be demonstrated that the optimal dose of sufentanil can be converted to minor doses of oral medication than expected from the calculated equi-analgesic ratios. Despite of lower oral opioid medication pain levels did not increase after conversion.

Conclusion: We recommend to begin opioid conversion with $10 \%$ of the calculated equivalent dose of intravenous sufentanil when converting to oral long-acting morphine and afterwards to further adapt the dosage.
\end{abstract}

\section{Introduction}

Since its development in the late 70s, sufentanil has an outstanding importance in clinical practice and one cannot think of surgery or intensive care routines without this treatment. The substance delivers a much higher potency than its parent drug fentanyl with an expanded therapeutic range [1,2]. From the beginning of its clinical use, sufentanil was the intravenous opioid of choice for hemodynamically instable patients [3]. Due to its outstanding hemodynamic stability resulting from a minor impact on cardiac index, left ventricular ejection fraction and heart rate [4], sufentanil is broadly used for critically ill patients in cardiac and non-cardiac surgery. In comparison with fentanyl, it has a shorter context-sensitive half time that results in better controllability [5] and predisposes the use of sufentanil in extended cases and for continuous infusion in intensive care.

The decoupling of analgesia and respiratory depression [6] is another reason for preferring sufentanil during weaning of mechanically ventilated patients or in those with spontaneous breathing. However, the routine use of continuous sufentanil analgosedation in the ICU may result in the problem that stabilized patients are still not free of pain or suffer from chronic pain and thus need to be converted to oral opioid medication, if discharged from the ICU after surgical or medical therapy. For example, common dosage of $20 \mu \mathrm{g}$ of sufentanil per hour has to be substituted by oral opioids as the patient should be transferred to the floor. The calculated equivalent dose for oral substitution would be $1440 \mathrm{mg}$ morphine per day, which is, of course, not practicable.

The following cases should demonstrate that sufficient pain therapy can be achieved also with significantly lower morphine doses. We report here six cases in which the hospital pain service was consulted to assist non-anesthetic intensive care units in the conversion from intravenous sufentanil to oral medication.

\section{Case Presentation}

Case 1: Patient J.S., male, 44 years old, weight $170 \mathrm{~kg}$, height $175 \mathrm{~cm}$; septic shock with multi-organ failure 
The patient who suffered from arterial hypertension, atrial fibrillation, type-II-diabetes mellitus and morbid adipositas was admitted due to severe and rapid deterioration of his general condition. He developed a septic shock with subsequent multiorgan failure including renal insufficiency requiring dialysis, and liver failure. Furthermore, he developed a cardiogenic shock with a left ventricular ejection fraction of about $10 \%$, and required cardio-pulmonary resuscitation (CPR) as ventricular fibrillation occurred.

After improvement and when the patient was able to be transferred to the floor, he received sufentanil infusion with $25 \mu \mathrm{g}$ per hour. The patient reported pain scores between NAS four and eight with burning quality. Pain therapy was converted orally to long-acting morphine (MST®, Mundipharma Ltd., Limburg an der Lahn, Germany) $3 \times 100 \mathrm{mg}$ and $30 \mathrm{mg}$ mirtazapine (REMERGILSolTab®, MSD Sharp \& Dohme GmbH, Haar, Germany) in the evening and short-acting morphine(Sevredol ${ }^{\circledR}$, Mundipharma Ltd., Limburg an der Lahn, Germany), 20mg up to six times daily on demand. After a stepwise reduction of the morphine dose down to $3 \times 30 \mathrm{mg}$ long-acting morphine per day and $30 \mathrm{mg}$ of mirtazapine, the pain service could sign off after seven days.

Case 2: Patient P.M., male, 63 years old, weight 97kg, height $180 \mathrm{~cm}$; serial rib fractures with pleural empyema

Table 1: Conversion from intravenous to oral opioid analgesics. In addition to morphine, $20 \mathrm{mg}$ of Sevredol p.o.,6-8 times/d on demand was prescribed. All patients received psychotropic drugs as co-medication to the opioids. Please note that the conversion did not affect the pain levels after the switch.

\begin{tabular}{|c|c|c|c|c|c|c|c|}
\hline Patient & $\begin{array}{c}\text { i.v. } \\
\text { Sufentanyl } \\
{[\mu \mathrm{g} / \mathrm{h}]}\end{array}$ & $\begin{array}{c}\text { Theoretical } \\
\text { Morphine } \\
\text { Dose per Day } \\
\text { [mg] }\end{array}$ & $\begin{array}{c}\text { de facto oral } \\
\text { Morphine [mg] }\end{array}$ & $\begin{array}{c}\text { Factual } \\
\text { Dose of the } \\
\text { Theoretical } \\
\text { Value [\%] }\end{array}$ & Co-Medication [mg] & Initial VAS & End VAS \\
\hline 1 & 25 & 1800 & $3 \times 100$ & 16,67 & mirtazapine (30) & $4(-8)$ & 3 \\
\hline 2 & 20 & 1440 & $3 \times 60$ & 12,5 & mirtazapine (15) & $5-6$ & 4 \\
\hline 3 & 40 & 2880 & $3 \times 100$ & 10,42 & pregabaline(2x150) & 5 & 3 \\
\hline 4 & $20^{*}$ & $1440\left(180^{*}\right)$ & $3 \times 100$ & 18,52 & carbamazepine $(3 \times 100)$ & $6(-8)$ & $3-4$ \\
\hline 5 & 20 & 1440 & $3 \times 100$ & 20,83 & pregabaline(150) & $5(-9)$ & 3 \\
\hline \multirow[t]{2}{*}{6} & 20 & 1440 & $3 \times 100$ & 20,83 & mirtazapine (15) & $3(-9)$ & 1 \\
\hline & & & & Mean: 16,63 & & & \\
\hline
\end{tabular}

*This patient received additionally transdermal fentanyl (Durogesic SMAT $75 \mu \mathrm{g} / \mathrm{h}$ )

The patient suffered from a traumatic left-sided rib series fracture and developed pneumonia and a pleural empyema while under conservative therapy. Secondary diagnoses comprised arterial hypertension, COPD, type-II-diabetes mellitus and chronic renal insufficiency. After surgical intervention and intensive care therapy with prolonged weaning, the patient was presented to the pain service for conversion to oral opioids. The current pain therapy was $20 \mu \mathrm{g} / \mathrm{h}$ of i.v. sufentanil (Table 1 ). The patient was switched to $3 \times 60 \mathrm{mg}$ long-acting morphine sulphate (MST®, Mundipharma Ltd., Limburg an der Lahn, Germany) and 15mg mirtazapine (REMERGIL SolTab®, MSD Sharp \& Dohme, Haar, Germany) in the evenings; additionally Sevredol ${ }^{\circledR} 20 \mathrm{mg}$ up to eight times daily was prescribed, if VAS exceeded 5 . After a stepwise reduction of the morphine dose down to $3 \times 30 \mathrm{mg}$ with an evening dose of $15 \mathrm{mg}$ mirtazapine, pain service consultation ended after four days, the patient being satisfied at VAS $<4$.

Case 3: Patient S.L., female, 53 years old, weight $146 \mathrm{~kg}$, height $170 \mathrm{~cm}$; sepsis with multiple arterial emboli

The patient was primarily treated for a sepsis with unknown focus and suffered from morbid adipositas, a history of hypertension and type-II-diabetes mellitus in the intensive care unit. During the clinical course, both legs had to be partially amputated due to multiple arterial emboli; the right leg below the knee, the left leg above.
Under sufentanil infusion of $40 \mu \mathrm{g} / \mathrm{h}$, the patient was presented for conversion to oral therapy. The initial regime comprised $3 \times 100 \mathrm{mg}$ of long-acting morphine with pregabaline (Lyrica ${ }^{\circledR}$, Pfizer $\AA$, Berlin, Germany), $2 \times 150 \mathrm{mg}$, and Sevredol ${ }^{\circledR}$, $20 \mathrm{mg}$ up to 6 times daily, if VAS exceeded 5 . The consultation ended after five days, with morphine dosage reduced to $3 \times 30 \mathrm{mg}$ of long-acting morphine and pregabaline $2 \times 150 \mathrm{mg}$. The patient was satisfied at VAS $<3$.

Case 4: Patient K.K., male, 58 years old, weight $104 \mathrm{~kg}$, height $180 \mathrm{~cm}$; osteomyelitis and acute renal failure after coronary arterial bypass grafting (CABG) surgery

The patient was treated for sternal osteomyelitis and acute renal failure after coronary arterial bypass grafting. In addition, the patient suffered from arterial hypertension, peripheral arterial vascular disease, hyperlipoproteinemia, COPD (GOLD III) and had been treated previously for laryngeal cancer with laryngectomy and bilateral neck dissection. At presentation to the pain service for conversion to oral medication, the patient received $20 \mu \mathrm{g} / \mathrm{h}$ sufentanil with additional transdermal fentanyl (Durogesic SMAT $75 \mu \mathrm{g} / \mathrm{h}$, JANSSEN-CILAG, Neuss, Germany), which the patient had already before surgery. Pain scores of VAS $=6$ with peaks at $\mathrm{VAS}=8$ were reported. The patient was converted to long-acting morphine $3 \times 100 \mathrm{mg} /$ day and additionally with $3 \times 100 \mathrm{mg}$ carbamazepine (Carbamazepin 
HEXAL $\AA^{\circledR}$, Salutas Pharma, Barleben, Germany) with opportunity of receiving supplementary $20 \mathrm{mg}$ Sevredol $\AA$, up to $8 \times$ per day. After reducing long-acting morphine to $2 \times 50 \mathrm{mg}$ with carbamazepine $3 \times 300 \mathrm{mg}$, pain service consultation ended after six days, the patient being satisfied at VAS $=3-4$.

Case 5: Patient R.S., male, 66 years old, weight $80 \mathrm{~kg}$, height $178 \mathrm{~cm}$; Multiple Myeloma and ARDS

The patient needed mechanical ventilation support for acute respiratory insufficiency under pre-existing multiple myeloma. During the clinical course, the patient developed acute renal failure requiring dialysis, aspiration pneumonia and critical illness polyneuropathy. After prolonged weaning, an apparently pain stricken patient was presented to the pain service receiving $20 \mu \mathrm{g} / \mathrm{h}$ sufentanil, for conversion to oral analgesics.

At pain levels of VAS $=5$ and peaks of VAS $=9$, initially longacting morphine $3 \times 100 \mathrm{mg} /$ day with $150 \mathrm{mg}$ pregabaline (Lyrica ${ }^{\circledR}$, Pfizer, Berlin, Germany) in the evenings was prescribed, with the possibility of additionally receiving $8 \times 20 \mathrm{mg}$ Sevredol@ per day. After stepwise reduction of morphine dose to $2 \times 20 \mathrm{mg} / \mathrm{d}$ of long-acting morphine and $150 \mathrm{mg}$ pregabaline in the evenings, the patient was discharged from the ICU with VAS $=3$ and the patient was discharged with $2 \times 10 \mathrm{mg} / \mathrm{d}$ longacting morphine and with $150 \mathrm{mg}$ pregabaline.

Case 6: Patient K.B., male, 62 years old, weight $60 \mathrm{~kg}$, height $160 \mathrm{~cm}$; hemorrhagic shock after bypass surgery of the femoral artery

Following bypass surgery of the femoral artery with secondary hemorrhage and hypovolemic shock, the patient developed an urosepsis. Preexisting diagnoses were peripheral vascular disease, arterial hypertension, type-2-diabetes mellitus and stage-III-renal insufficiency. After stabilizing the patient and planning for discharge to the ward, pain service was consulted for conversion of i.v. Sufentanil, $20 \mu \mathrm{g} / \mathrm{h}$, to oral medication.

The patient described pain as having piercing/stabbing qualities at $\mathrm{VAS}=3$, peaking at $\mathrm{VAS}=9$. After a stepwise reduction of initially $3 \times 100 \mathrm{mg} /$ day long-acting morphine with mirtazapine $15 \mathrm{mg}$ for the night, the patient was discharged from the ICU with $3 \times 60 \mathrm{mg} / \mathrm{d}$ long-acting morphine with afore mentioned mirtazapine at VAS $=1$.

\section{Discussion}

In clinical practice, sufentanil is indispensable for anesthesia and intensive care therapy. However, a conversion from continuous sufentanil infusion to oral opioid medication is essential for discharge from the ICU; however, current literature offers no usable conversion algorithms.

The pain levels of a series of six patients presented here indicate that opioid conversion to lower oral doses does not result in an increase of pain scores. Additionally administered psychotropic drugs may also have an effect on alleviating pain, yet two aspects have to be taken into account: (1) pain aggravation by under-dosing of opioids cannot be compensated by psychotropic medication, and (2) if the opioid dose is titrated to an optimum, psychotropic drugs cannot further reduce this dose. They can only be used to avoid severe side effects of opioid therapy [7]. In the present cases, psychotropic medication was used to treat effects of opioid over-dosing after conventional conversion, and was needed to treat the neuropathic aspects of the respective pain qualities [8].

It is important to note that the conversion to oral opioids is not an "opioid rotation“, although one has to calculate an equianalgetic dose. The concept of opioid rotation addresses the problem of excessive side effects [9] of a single opioid or the insufficient effect on pain $[9,10]$. This was not the case in the presented patients. In those, we intended to switch an i.v. opioid to an orally applied one, much in the way a morphine drip is switched to oral retarded morphine.

Sufentanil is available as a non-i.v. preparation for sublingual, buccal and nasal administration but not in a longacting formulation. As the application route switch is usually for a single compound and the long-acting formulation is commercially unavailable, change to long-acting morphine was necessary, but not in the sense of an opioid rotation.

In current references, only the general recommendation to begin oral substitution with approximately $50 \%$ of the equivalent dose can be found $[10,11]$. These recommendations are based on the thought that on one hand the patients have not benefitted from the current opioid and on the other they offer concomitant clinical limitations (i.e. advanced age, renal damage, cardiopulmonary insufficiency, etc.) that makes a 1:1 switch to a new opioid inappropriate.

The patients in the presented cases had an i.v. sufentanil medication near the optimum dose. The available conversion tables and factors suggested a $900 \%$ higher dosing than that we eventually applied. Even with a reduction of $50 \%$ from the given i.v. dose, the orally administered amount would still have been in excess of $350 \%$ of the dose that is finally necessary. This is striking, as inadequately high doses of opioids can lead to severe side effects such as attention deficits, optical hallucinations and ultimately respiratory depression $[12,13]$.

From the present data, we provide evidence that, when converting i.v. sufentanil to oral morphine, a much steeper reduction of the equivalent dose is urgently warranted.

We would like to recommend starting with $10-20 \%$ of the calculated equivalent dose of sufentanil infusion when converting to oral long-acting morphine and afterwards adapting the morphine dosage further. Possible co-medication with neuroleptics and benzodiazepines should not be ignored in order to further minimize opioid doses and to decrease severe side effects. 
In the possible case that the conversion to a long-acting opioid proves insufficient, a similar approach as usually followed in opioid conversion should be used: In addition to the estimated dose, rescue medication needs to be provided. This can be claimed every hour by the patient and, in the case of using morphine sulfate, doses of $10 \mathrm{mg}$ and $20 \mathrm{mg}$ with an onset of 15 to 20 minutes should be available. It seems important that none of our patients claimed rescue medication.

\section{Conclusion}

Owing to safety considerations, we propose to approach the final opioid dose from a lower dose. By doing this, severe side effects and a possible readmission to the intensive care unit can be avoided. Moreover, since the increased pain perception precedes withdrawal symptoms, correcting the opioid dose in an hourly interval would not have led to withdrawal indicators [14-18].

\section{References}

1. Niemegeers CJ, Schellekens KH, Van Bever WF, Janssen PA (1976) Sufentanil, a very potent and extremely safe intravenous morphinelike compound in mice, rats and dogs. Arzneimittelforschung 26(8): 1551-1556.

2. Zollner C, Schafer M (2008) [Opioids in anesthesia]. Der Anaesthesist 57(7): 729-740

3. Bovill JG, Sebel PS, Stanley TH (1984) Opioid analgesics in anesthesia: with special reference to their use in cardiovascular anesthesia. Anesthesiology 61(6): 731-755.

4. Bhavsar R, Sloth E, Folkersen L, Greisen JR, Jakobsen CJ (2011) Sufentanil preserves hemodynamics and left ventricular function in patients with ischemic heart disease. Acta Anaesthesiol Scand 55(8): 1002-1009.

5. Hughes MA, Glass PS, Jacobs JR (1992) Context-sensitive half-time in multicompartment pharmacokinetic models for intravenous anesthetic drugs. Anesthesiology 76(3): 334-341.

6. Bailey PL, Streisand JB, East KA, East TD, Isern S, et al. (1990)
Differences in magnitude and duration of opioid-induced respiratory depression and analgesia with fentanyl and sufentanil. Anesth Analg $70(1): 8-15$

7. Brinkers M, Pfau G, Voigt A, Schneemilch C (2015) [Pain therapy in patients with schizoaffective disorder and cancer]. Schmerz 29(2): 217-222.

8. Finnerup NB, Otto M, McQuay HJ, Jensen TS, Sindrup SH (2005) Algorithm for neuropathic pain treatment: an evidence based proposal. Pain 118(3): 289-305.

9. Knotkova H, Fine PG, Portenoy RK (2009) Opioid rotation: the science and the limitations of the equianalgesic dose table. J Pain Symptom Manage 38(3): 426-439.

10. Fine PG, Portenoy RK (2009) Establishing "best practices" for opioid rotation: conclusions of an expert panel. J Pain Symptom Manage 38(3): 418-425.

11. Freye E, Latasch L (2003) [Development of opioid tolerance -molecular mechanisms and clinical consequences]. AINS 38(1): 14-26.

12. Schuler M, Griessinger N (2015) [Opioids for noncancer pain in the elderly]. Schmerz 29(4): 380-401.

13. Aubrun F, Bunge D, Langeron O, Saillant G, Coriat P, et al. (2009) [Postoperative morphine administration in the elderly patient]. Anesthesiology 99(1): 160-165.

14. Redding SE, Liu S, Hung WW, Boockvar KS (2014) Opioid interruptions pain, and withdrawal symptoms in nursing home residents Clin Ther 36(11): 1555-1563.

15. Kroll W, List WF (1997) Pain treatment in the ICU: intravenous, regional or both? Eur J Anaesthesiol Suppl 15: 49-52.

16. Whipple JK, Lewis KS, Quebbeman EJ, Wolff M, Gottlieb MS, et al. (1995) Analysis of pain management in critically ill patients. Pharmacotherapy 15(5): 592-599.

17. Fragen RJ (1997) Pharmacokinetics and pharmacodynamics of midazolam given via continuous intravenous infusion in intensive care units. Clin Ther 19(3): 405-419.

18. Martin J, Franck M, Sigel S, Weiss M, Spies C (2007) Changes in sedation management in German intensive care units between 2002 and 2006 : a national follow-up survey. Crit Care 11(6): R124.

Your next submission with Juniper Publishers will reach you the below assets

- Quality Editorial service

- Swift Peer Review

- Reprints availability

- E-prints Service

- Manuscript Podcast for convenient understanding

- Global attainment for your research

- Manuscript accessibility in different formats ( Pdf, E-pub, Full Text, Audio)

- Unceasing customer service

Track the below URL for one-step submission

https://juniperpublishers.com/online-submission.php 